\title{
Oral Commissure Defect Reconstruction with Modified Biflanged Submental Artery Island Flap
}

\author{
${ }^{1}$ Anju Mathai, ${ }^{2}$ Satheesan Balasubramanian, ${ }^{3}$ Sajith Babu
}

\section{ABSTRACT}

Reconstruction of defects in the commissure region with buccal and lip defects is difficult to reconstruct with regional flap. A case report of a case reconstructed with a new design of the submental flap is described with its advantages.

Keywords: Oral cancer, Commissure, Submental flap.

How to cite this article: Mathai $A$, Balasubramanian $S$, Babu S. Oral Commissure Defect Reconstruction with Modified Biflanged Submental Artery Island Flap. Int J Head Neck Surg 2015;6(1):38-40.

Source of support: Nil

Conflict of interest: None

\section{INTRODUCTION}

Reconstruction of defects in the commissure of oral cavity is always challenging. Several reconstructive options are available with the use of both local flaps and free flaps. The local flaps are often inadequate as single flap can cover only one side of the defect, either the portion of the lower lip or the portion of the upper lip whereas double flaps are cumbersome. The locoregional flaps which can be used are tongue flap, nasolabial flap, forehead flap, infrahyoid flap and submental flap. Free flap has the advantage of being pliable, moldable tissue, but has the disadvantage of mismatch in color, technical expertise and more time required.

Submental artery island flap (SAIF) has been used for reconstruction of various defects in oral cavity. This flap which is based on the submental artery is a local flap, which is easy to harvest and less disfiguring. We have modified the use of submental flap to reconstruct a commissure defect by using a biflange at the nonhair-bearing area.

\section{CASE REPORT}

A 50-year-old gentleman presented with ulcerative lesion in the left commissure of 2 months duration. He

\footnotetext{
${ }^{1}$ Fellow, ${ }^{2}$ Professor, ${ }^{3}$ Associate Professor

${ }^{1-3}$ Department of Surgical Oncology, Malabar Cancer Centre Kannur, Kerala, India

Corresponding Author: Sajith Babu, Associate Professor Department of Surgical Oncology, Malabar Cancer Centre Kannur, Kerala, India, Phone: 919895468081, e-mail: drsajith@gmail.com
}

was a chronic beedi smoker for past 25 years with 10 to 15 beedies per day. On clinical examination, he had an ulceroproliferative lesion of $3 \times 2.5 \mathrm{~cm}$ size involving the oral commissure and extending to left side of upper lip, lateral portion of lower lip and buccal mucosa (Fig. 1). There was a non-homogenous leukoplakia in the lower lip at the edge of the lesion. Biopsy of the ulcerative lesion was well-differentiated carcinoma. There were no significant lymph nodes in the neck. He underwent wide excision of the lesion with $1 \mathrm{~cm}$ margin and ipsilateral selective neck dissection. The defect included $2 \mathrm{~cm}$ of upper lip, $2 \mathrm{~cm}$ of lower lip, commissure and $4 \times 2.5 \mathrm{~cm}$ of buccal mucosa (Fig. 2). Reconstruction was done with biflanged submental artery island flap. The flap was designed based on the ipsilateral submental artery. A vertical design of the flap with an ellipse of $4 \times 3 \mathrm{~cm}$ size at the midline of the submental region from hyoid to the mentum. The inferior part of the flap was extended below the level of the hyoid for $2 \mathrm{~cm}$ with two flanges to repair the upper and lower lip (Fig. 3). The flap was raised after dissecting the submental and submandibular levels. The flap was then taken into the defect through a paramandibular dissection lateral to mandible. The rest of the neck dissection was completed. Oral feeds were started on third postoperative day and there was good oral competence. Adjuvant radiotherapy was not given as the histopathology was pT2N0 with no adverse factors. On follow-up, the patient has a good cosmetic outcome with a well-maintained commissure (Figs 4 and 5). Hair growth was seen in the buccal part of the flap which decreased after 6 months. The flap gave good commissure contour with good cosmesis and oral competence (Fig. 6). The mouth opening was allowing more than three finger between incisors (Fig. 7). The donor site healed well and was well hidden under the submental region (Fig. 8).

\section{DISCUSSION}

Oral commissure reconstruction is challenging as symmetry and oral competence are to be restored. Various attempts had been made with large number of options for many decades. ${ }^{1,2}$ Local flap from the buccal region, cervical region and face was used previously. ${ }^{3-8}$ Radial forearm and anterolateral thigh free flap have been found to be very useful. ${ }^{9-13}$ 
Submental artery flap was first described by Martin et al in 1993 and was used in defects after oncological resection by Sterne and Hall in $1996{ }^{14,15}$ There have been many reports regarding the oncological safety of the flap. ${ }^{16}$ In selected patients, the SAIF has been found to be safe option.

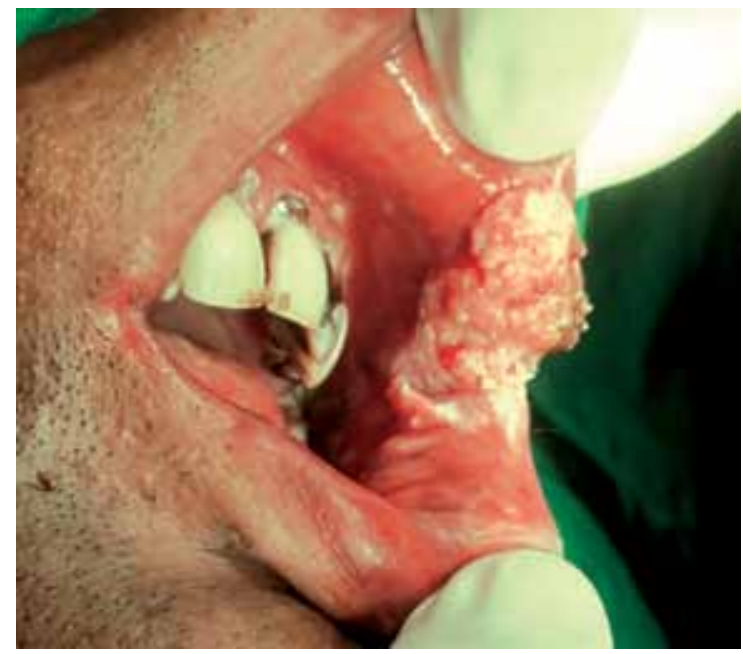

Fig. 1: Preoperative carcinoma of left commissure with extension to upper lip, lower lip and buccal mucosa

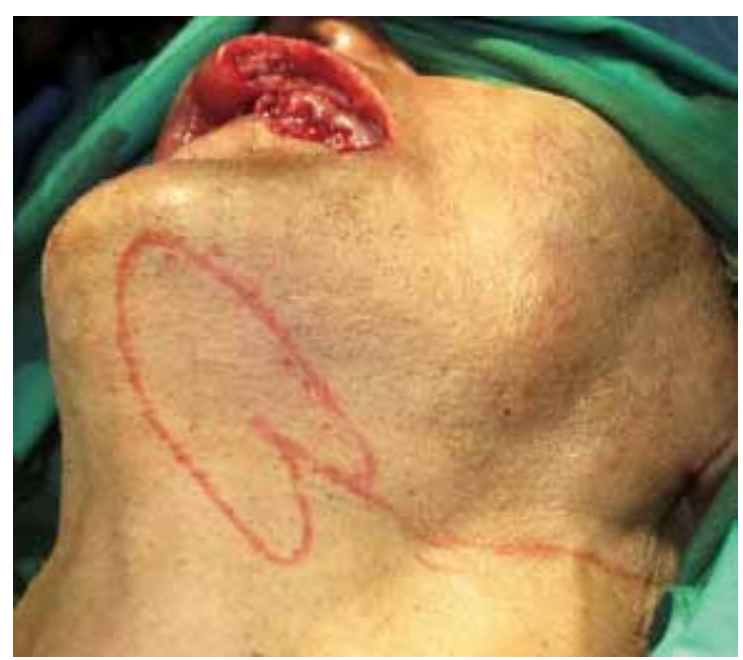

Fig. 3: Flap marked in the submental region with biflange marked in nonhair-bearing area

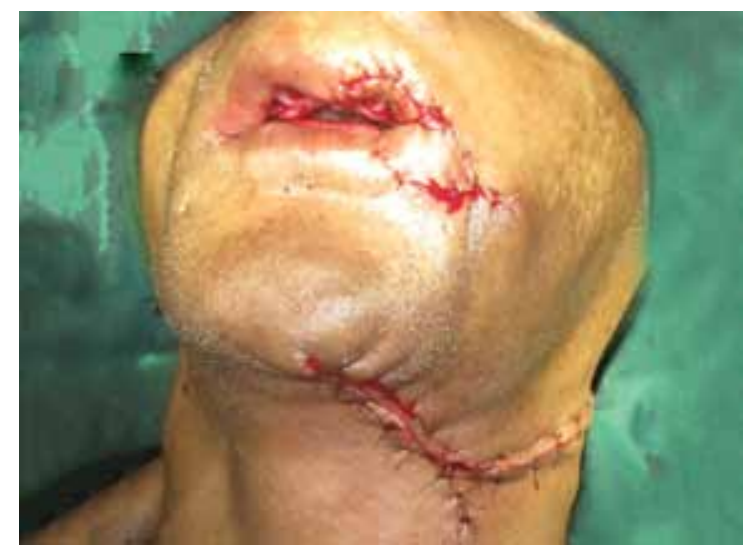

Fig. 5: Flap inset to the defect with the biflanged portion for the lip and commissure
Submental artery island flap is based on the submental branch of facial artery. It is usually used as a pedicled flap. The submental artery branches about $27.5 \mathrm{~mm}$ from the origin of the facial artery, just deep to the submandibular gland. The diameter of the submental artery is $1.7 \mathrm{~mm}$ at the origin and the total length of the submental

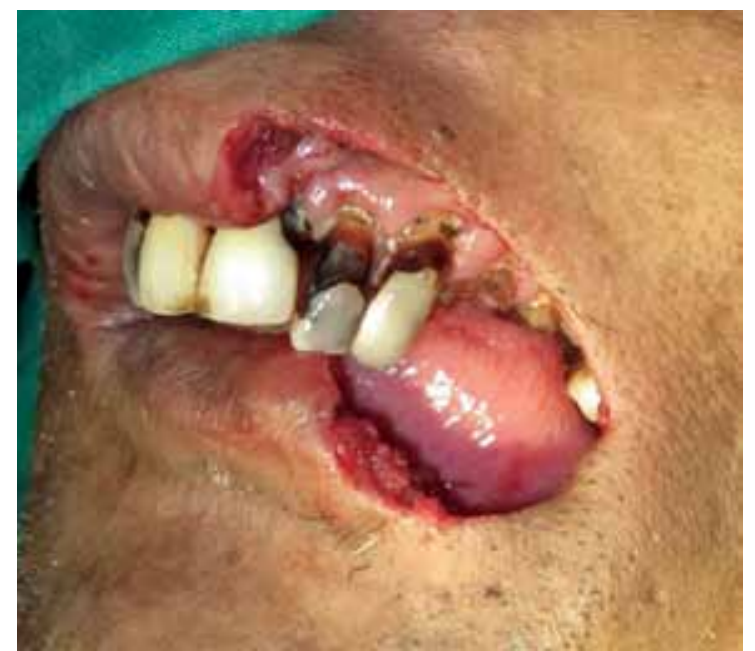

Fig. 2: Defect after excision of lesion

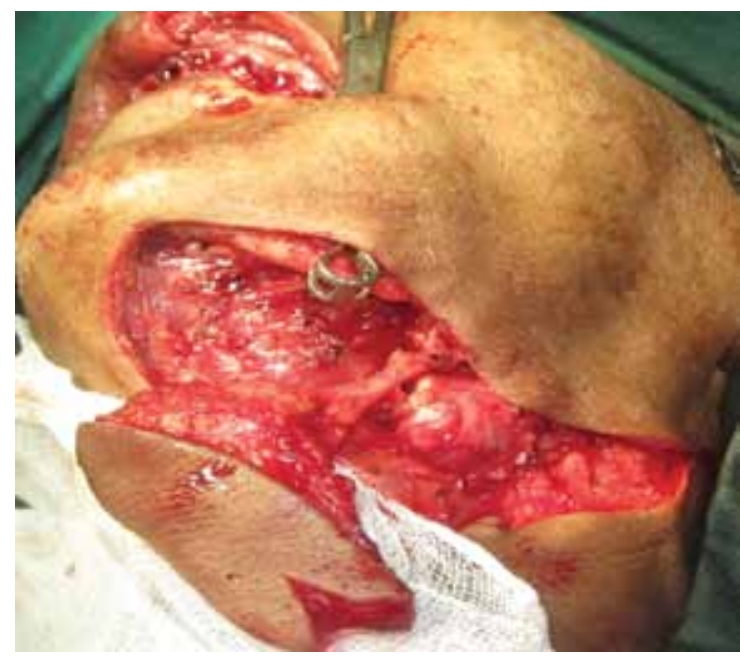

Fig. 4: Flap raised based on submental artery as an islanded flap

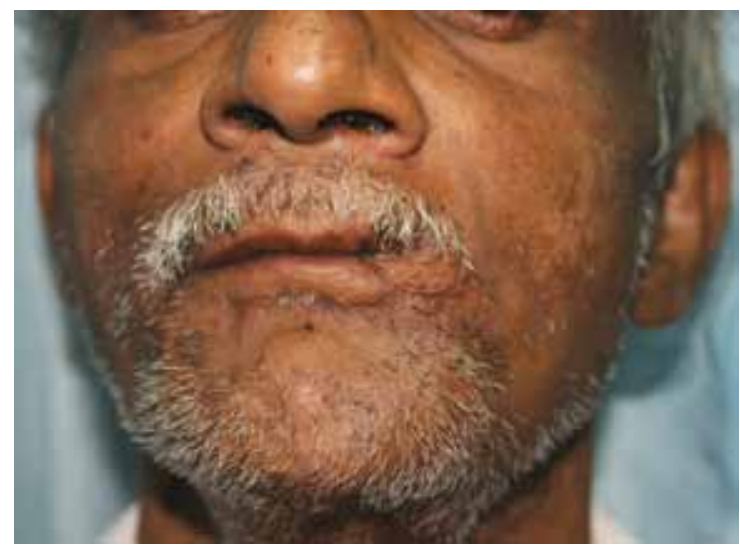

Fig. 6: Postoperative good cosmesis with competence of commissure 


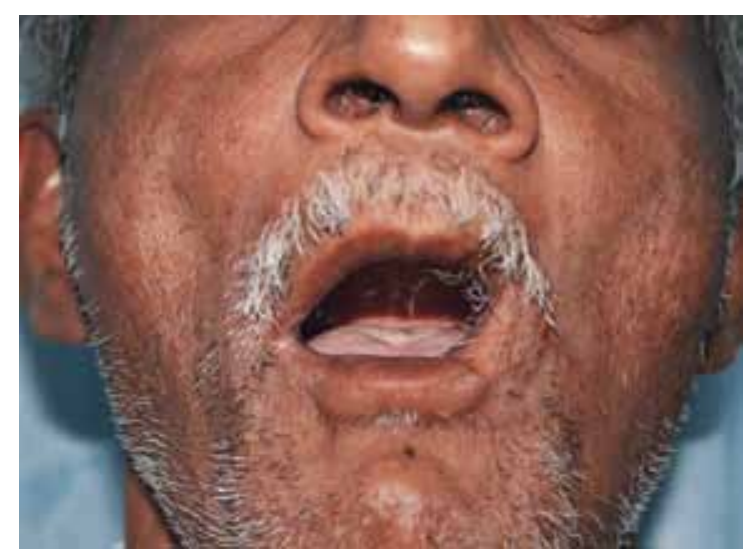

Fig. 7: Postoperative good mouth opening

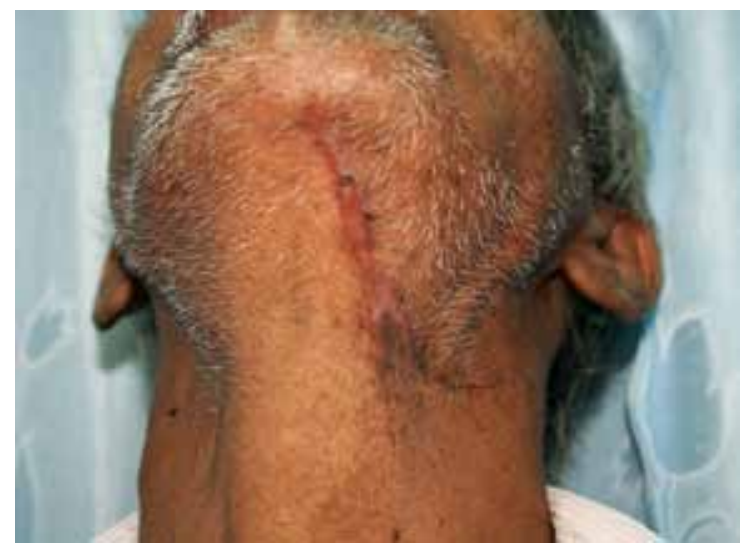

Fig. 8: Healed scar in the submental region

artery is about $58.9 \mathrm{~mm}$. It runs in a groove medial to submandibular gland superficial to mylohyoid muscle deep and inferior to the body of mandible. The artery ends behind the symphysis just lateral to midline. The branches of the submental artery are: to submandibular gland, to platysma, mylohyoid, digastric, periosteum of mandible, small branch to subplatysmal fatty layer, one to four cutaneous perforators based on which the skin paddle can be raised. Submental vein drains into facial vein which lies superficial to artery and runs along the same course.

The advantage of a SAIF is that the flap is easily available, easy to harvest and no donor site morbidity, whereas the disadvantages are the hair growth seen in male patients and restriction of size of donor in thin patients. The contraindication for harvesting a SAIF is the presence of nodal metastasis at level IA or IB.

\section{CONCLUSION}

Submental artery island flap with a modification by extending to make biflange is a viable option in reconstruction of the commissural defects in elderly patients with cancers of commissure without nodal metastasis.

\section{REFERENCES}

1. Naasan A,Quaba AA. Reconstruction of theoral commissureby vascularised toe web transfer. Br J Plast Surg 1990 May;43(3): 376-378.

2. Eriksson E, Johanson B. Reconstruction of the oral commissure with Z-plasties. Case Report. Scand J Plast Reconstr Surg 1982;16(3):305-306.

3. Burusapat C, Pitiseree A. Advanced squamous cell carcinoma involving both upper and lower lips and oral commissure with simultaneous reconstruction by local flap: a case report. J Med Case Rep 2012 Jan 18;6:23.

4. Rifaat MA. Reconstruction of medium-sized thickness of oral commissure by combining double full-thickness cheek rhomboid flap and a small lip switch flap. Ann Plast Surg 2011 Aug;67(2):134-138.

5. Jhamb A, Mohanty S. A technique for functional and aesthetic reconstruction of the oral commissure and buccal mucosa. Int J Oral Maxillofac Surg 2010 Mar;39(3):287-289.

6. Robotti E, Righi B, Carminati M, et al. Oral commissure reconstruction with orbicularis oris elastic musculomucosal flaps. J Plast Aesthet Reconstr Surg 2010 Mar;63(3):431-439.

7. Yamauchi M, Yotsuyanagi T, Ezoe K, Saito T, Yokoi K, Urushidate S. Estlander flap combined with an extended upper lip technique for large defects of lower lip with oral commissure. J Plast Reconstr Aesthet Surg 2009 Aug;62(8):997-1003.

8. Demir Y, Latifoglu O, Yavuzer R, Atabay K. Oral commissure reconstruction with split masseter muscle transposition and cheek skin flap. J Craniomaxillofac Surg 2001 Dec;29(6):351-354.

9. Sasaki K, Adachi K, Sekido M. Transverse fascial suspension with muscle bow traction: advantages for full-thickness lip reconstruction involving the oral commissure using free flap. J Plast Reconstr Aesthet Surg 2012 Jul;65(7):e193-e196.

10. Valentini V, Saltarel A, Cassoni A, Battisti A, Egidi S. Onestage reconstruction of a defect of the oral commissure and of the cheek with a radial forearm free flap. J Craniofac Surg 2008 Nov;19(6):1508-1511.

11. Jeng SF, Kuo YR, Wei FC, Su CY, Chien CY. Reconstruction of concomitant lip and cheek through-and-through defects with combined free flap and an advancement flap from the remaining lip. Plast Reconstr Surg 2004 Feb;113(2):491-498.

12. Huang WC, Chen HC, Jain V, Kilda M, Lin YD, Cheng $\mathrm{MH}$, Lin SH, Chen YC, Tsai FC, Wei FC. Reconstruction of through-and-through cheek defects involving the oral commissure, using chimeric flaps from the thigh lateral femoral circumflex system. Plast Reconstr Surg 2002 Feb;109(2):433441;Discussion 442-443.

13. YokooS1, Tahara S, Tsuji Y, Nomura T, Hashikawa K, Hanagaki H, Furudoi S, Umeda M, Komori T. Functional and aesthetic reconstruction of full-thickness cheek, oral commissure and vermilion. J Craniomaxillofac Surg 2001 Dec;29(6):344-350.

14. Martin D1, Pascal JF, Baudet J, Mondie JM, Farhat JB, Athoum A, Le Gaillard P, Peri G. The submental island flap: a new donor site. Anatomy and clinical applications as a free or pedicled flap. Plast Reconstr Surg 1993 Oct;92(5):867-873.

15. Sterne GD, Januszkiewicz JS, Hall PN, Bardsley AF. The submental island flap. Br J Plast Surg 1996 Mar;49(2):85-89.

16. Sebastian P, Thomas S, Varghese BT, Iype EM, Balagopal PG, Mathew PC. The submental island flap for reconstruction of intraoral defects in oral cancer patients. Oral Oncol 2008 Nov; 44(11):1014-1018. 